\title{
Association of miR-182 expression in amniotic fluid with intrauterine infection and brain injury in premature infants
}

\author{
FENGCHUN GAO, XIAOJUAN JIANG, QIRONG LI and KEFENG FAN
}

Department of Obstetrics, Jinan Maternity and Child Care Hospital, Jinan, Shandong 250001, P.R. China

Received November 1, 2017; Accepted May 23, 2018

DOI: $10.3892 / \mathrm{etm} .2018 .6365$

\begin{abstract}
Changes of micro-ribonucleic acid-182 (miR-182) level in cases of intrauterine infection were investigated to explore the association between miR-182 level change and brain injury in premature infants. A total of 257 preterm infants born in obstetrics department of Jinan Maternity and Child Care Hospital from February 2015 to February 2017 were enrolled in this study. These preterm infants were divided into infected group ( $\mathrm{n}=113)$ and uninfected group $(n=144)$ based on pathological diagnosis results. Quantitative polymerase chain reaction (qPCR) was employed to detect miR-182 level in amniotic fluid. Bregmatic sagittal and coronal plus lateral fontanel craniocerebral ultrasound, craniocerebral computed tomography (CT) and craniocerebral magnetic resonance imaging examinations were conducted in these preterm infants within one week after birth, and the results were recorded. The relationship between intrauterine infection and brain injury in premature infants was analyzed, and the association of miR-182 level with brain injury was explored. According to pathological diagnoses, brain injury was found in 61 of 113 infants in the infected group, with an incidence rate of $54.0 \%$; and 28 of 144 infants in uninfected group, with an incidence rate of 19.4\%; among them, 3 had placental infection caused by intrauterine infection in pregnant women, and all preterm infants had brain damage. Risk value of brain injury in premature infants due to intrauterine infection was hazard ratio $(\mathrm{HR})=2.2611, \chi^{2}=33.798, \mathrm{P}<0.02$. Infected group had a higher miR-182 level in comparison with uninfected group, and the difference in miR-182 level between infected group and uninfected group was statistically significant $(\mathrm{P}<0.05)$. Intrauterine infection can lead to an increase in miR-182 level; growth in miR-182 level is closely related to brain injury in premature infants.
\end{abstract}

Correspondence to: Dr Kefeng Fan, Department of Obstetrics, Jinan Maternity and Child Care Hospital, 2 Jianguoxiaojingsan Road, Jinan, Shandong 250001, P.R. China

E-mail: efnmgi@163.com

Key words: miR-182, intrauterine infection, brain injury in premature infants, CT, imaging diagnosis

\section{Introduction}

Intrauterine infection in pregnant women is a common disease in gynecology and obstetrics and also an important factor leading to neonatal premature birth, resulting in $\sim 40 \%$ of premature infants (1), and it causes hypoplasia of neonatal organ function, or even death (2). Ways leading to intrauterine infection are mainly vaginal and cervical elevation, placental infection, retrograde infection in abdominal cavity and invasive operation. The most severe stage of intrauterine infection elevation is fetal infection, causing neonatal sepsis or even death (3).

Preterm birth has serious adverse reactions on the integrity of neonatal brain structure and function (4). A study showed that (5), gray matter and white matter volumes in brains of premature infants are less than those in brains of normally born infants, which may cause cognitive and neural defects in pediatric patients when the pathology is severe. Increasing number of people think that inflammation is a key factor for normal development and damage outcome of immature brains. Perinatal neuroinflammation can increase risks of nerve system diseases and neuropsychiatric disorders in childhood and adult stage (6).

Micro-ribonucleic acid-182 (miR-182) is a highly conserved polycistronic miR cluster located within the $5-\mathrm{kb}$ region of human chromosome 7q32.2. Studies have shown that $(7,8)$ miR-182 is aberrantly expressed in multiple tumors, and is directly involved in the occurrence and development of human cancers, but the mechanism of action of miR-182 in tumors remains unclear. It can act as an oncogene or tumor suppressor gene, depending on the type, location and stage of the cancer.

The present study detected the expression level of miR-182 in amniotic fluid of the pregnant women to explore its associations with intrauterine infection and brain injury in premature infants.

\section{Subjects and methods}

Subjects. A total of 257 premature infants delivered in obstetrics department of Jinan Maternity and Child Care Hospital from February 2015 to February 2017 were selected, including 140 male infants and 117 female infants, with an average time of pregnancy termination of $34.1 \pm 2.5$ weeks and a mean weight of premature infants of $2.4 \pm 0.9 \mathrm{~kg}$. Premature infants who had 
Table I. Main instruments and reagents.

Instrument and reagent

Manufacturer

\section{H\&E kit}

SonoSite portable color ultrasound

GE prospeed CT

PCR instrumentation

TRIzol kit

TaqMan ${ }^{\circledR}$ miR reverse transcription kit

Agarose

U6 internal reference primer

\author{
Beyotime, Shanghai, China \\ SonoSite Inc., Bothell, WA, USA \\ Beijing Deanren Technology Co., Ltd. (Beijing, China) \\ Bio-Rad Laboratories, Inc., Hercules, CA, USA \\ Invitrogen; Thermo Fisher Scientific, Inc., Waltham, MA, USA \\ Thermo Fisher Scientific Inc., Beijing, China \\ Sigma-Aldrich; Merck KGaA, Darmstadt, Germany \\ GenScript, Jiangsu, China
}

$\mathrm{H} \& \mathrm{E}$, hematoxylin and eosin; CT, computed tomography; PCR, polymerase chain reaction.

a time of pregnancy termination of shorter than 35 weeks and whose mother did not have preeclampsia or diabetes mellitus were included in this study. This study was approved by medical Ethics Committee of Jinan Maternity and Child Care Hospital (Shandong, China). Parents of the patients signed the informed consent.

Methods. Main instruments and reagents used are listed in Table I.

H\&E staining: Puerperal placental tissues were collected from pregnant women and subjected to H\&E staining. After staining, extent of inflammatory response in samples was observed under an optical microscope and expressed as leukocyte infiltration degree.

Diagnostic basis of intrauterine infection (9): leukocyte infiltration $2+$ or above; heart rate of the pregnant woman $>100$ beats/min or fetal heart rate $>160$ beats $/ \mathrm{min}$, body temperature of the pregnant woman $>37.5^{\circ} \mathrm{C}$; leukocyte count $>15 \times 10^{9} / 1$; peculiar smell was found in amniotic fluid; and there was uterine body tenderness (positive).

Diagnostic basis of brain injury (10): imageological examination was used as the diagnostic basis, and fetuses received craniocerebral magnetic resonance imaging, computed tomography (CT), ultrasound diagnosis of brain injury within one week after birth. Brain injury could be considered if one of the above was met.

RNA extraction. TRIzol reagents were used for the extraction of total RNA in amniotic fluid, and steps were carried out according to instructions provided by Invitrogen (Thermo Fisher Scientific, Inc., Waltham, MA, USA). An ultraviolet spectrophotometer was utilized to analyze the concentration and purity of the extracted RNA, and 3\% agarose gel electrophoresis was applied to analyze the integrity of RNA. Total RNA was taken to synthesize complementary deoxyribonucleic acid (cDNA) using the RT Revert Aid First Strand cDNA Synthesis kit and Moloney Murine Leukemia Virus (M-MLV) Reverse Transcriptase (both from Thermo Fisher Scientific, Inc.)

cDNA synthesis. cDNA was synthesized with reverse transcriptase based on relevant instructions. Reaction: $37^{\circ} \mathrm{C}$ for $45 \mathrm{~min}$ and $95^{\circ} \mathrm{C}$ for $5 \mathrm{~min}$. The product was stored at $-20^{\circ} \mathrm{C}$.
Quantitative PCR ( $q P C R)$. The reaction system volume was in total $25 \mu \mathrm{l}$, pre-denaturation at $95^{\circ} \mathrm{C}$ for $5 \mathrm{~min}$, denaturation at $95^{\circ} \mathrm{C}$ for $30 \mathrm{sec}$, annealing at $60^{\circ} \mathrm{C}$ for $45 \mathrm{sec}$, extension at $72^{\circ} \mathrm{C}$ for $3 \mathrm{~min}$, with 35 cycles, and then extension at $72^{\circ} \mathrm{C}$ for $5 \mathrm{~min}$. PCR products were stored at $4^{\circ} \mathrm{C}$. Upstream primer of miR-182 was 5'-TGCGGTTTGGCAATGGTAGAAC-3', and its downstream primer was 5'-CCAGTGCAGGGTCCGAGGT-3'; U6 was used as the internal inference of reaction. Quantitative analysis was carried out using the ABI 7500 fluorescence PCR amplification instrument (Applied Biosystems; Thermo Fisher Scientific, Inc.). All samples were repeated on 3 wells and the results were analyzed using $2^{-\Delta \Delta \mathrm{Cq}}$ method (11).

Statistical analysis. Statistical Product and Service Solutions (SPSS) 19.0 software package (IBM Corp., Armonk, NY, USA) was used to analyze data obtained from this study. Chi-square test was used for enumeration data. Measurement data were expressed as mean \pm standard deviation. Independent Student's t-test was employed for data comparison between two groups. COX regression analysis was utilized to analyze associations of miR-182 expression level with intrauterine infection and brain injury in premature infants. $\mathrm{P}<0.05$ was considered to indicate a statistically significant difference.

\section{Results}

General information. A total of 257 premature infants born in Jinan Maternity hospital from February 2015 to February 2017 were selected. They were divided into infected group $(n=113)$, with a gestational age of $33.7 \pm 2.4$ weeks and a body weight of $2.2 \pm 0.8 \mathrm{~kg}$, and uninfected group $(\mathrm{n}=144)$, with a gestational age of $34.5 \pm 3.3$ weeks and a body weight of $2.8 \pm 0.7 \mathrm{~kg}$ based on pathological diagnoses. There was no difference in sex between the groups $(\mathrm{P}>0.05)$. There was no difference in sex, gestational age and body weight between the two groups ( $P>0.05)$, and the IL-6 level, heart rate and white blood cell count in the infected group were significantly higher than those in the non-infected group $(\mathrm{P}<0.05)$ (Table II).

Diagnostic results of infection in pregnant women. A total of 61 premature infants with brain injury were found in infected group, and the incidence rate was $54.0 \%$; while in uninfected 
Table II. Comparison of clinical data of premature infants in infected group and uninfected group.

\begin{tabular}{|c|c|c|c|}
\hline Clinical data & $\begin{array}{l}\text { Infected } \\
\text { group } \\
(\mathrm{n}=113)\end{array}$ & $\begin{array}{l}\text { Uninfected } \\
\text { group } \\
(\mathrm{n}=144)\end{array}$ & P-value \\
\hline Sex (male/female) & $62 / 51$ & $65 / 79$ & 0.568 \\
\hline $\begin{array}{l}\text { Mother's body } \\
\text { temperature }\left({ }^{\circ} \mathrm{C}\right)\end{array}$ & $38.1 \pm 0.2$ & $37.2 \pm 0.3$ & 0.824 \\
\hline Gestational age (weeks) & $33.7 \pm 2.4$ & $34.5 \pm 3.3$ & 0.775 \\
\hline Body weight (kg) & $2.2 \pm 0.8$ & $2.8 \pm 0.7$ & 0.698 \\
\hline $\begin{array}{l}\text { Method of delivery } \\
\text { Spontaneous labor } \\
\text { Cesarean section }\end{array}$ & $\begin{array}{l}68(60.18) \\
45(39.82)\end{array}$ & $\begin{array}{l}88(61.11) \\
56(38.89)\end{array}$ & 0.856 \\
\hline $\begin{array}{l}\text { Premature infant } \\
\text { with brain injury }\end{array}$ & $61(54.0 \%)$ & $28(19.4 \%)$ & 0.023 \\
\hline IL-6 ( $\mu \mathrm{g} / \mathrm{l})$ & $6.82 \pm 3.59$ & $2.61 \pm 1.22$ & 0.024 \\
\hline $\begin{array}{l}\text { Heart rate of premature } \\
\text { infants (beats/min) }\end{array}$ & $181.2 \pm 10.3$ & $144.5 \pm 11.6$ & 0.031 \\
\hline $\begin{array}{l}\text { Leukocyte count }\left(\times 10^{9} /\right) \\
\text { in cord blood }\end{array}$ & $18.2 \pm 1.3$ & $9.5 \pm 1.9$ & 0.027 \\
\hline
\end{tabular}

IL-6, interleukin-6.

Table III. Diagnostic results of infections in pregnant women.

\begin{tabular}{|c|c|c|}
\hline Infections & $\begin{array}{l}\text { Infected } \\
\text { group } \\
(\mathrm{n}=113)\end{array}$ & $\begin{array}{l}\text { Uninfected } \\
\text { group } \\
(\mathrm{n}=144)\end{array}$ \\
\hline Leukocyte infiltration degree & $2+/ 3+$ & $-/+$ \\
\hline $\begin{array}{l}\text { Heart rate of } \\
\text { the pregnant woman }\end{array}$ & $112.3 \pm 12.5$ & $90.6 \pm 10.1$ \\
\hline Fetal heart rate & $181.2 \pm 10.3$ & $144.5 \pm 11.6$ \\
\hline $\begin{array}{l}\text { Body temperature of } \\
\text { the pregnant woman }\end{array}$ & $38.1 \pm 0.2$ & $37.2 \pm 0.3$ \\
\hline Leukocyte count & $18.2 \pm 1.3$ & $9.5 \pm 1.9$ \\
\hline Peculiar smell in amniotic fluid & Positive & Negative \\
\hline Uterine body tenderness & Positive & Negative \\
\hline
\end{tabular}

group, there were 28 premature infants with brain injury, with an incidence rate of $19.4 \%$; 3 had placental infection caused by intrauterine infection in pregnant women, and all premature infants had brain injury (Table III).

Expression level of miR-182 in infected and uninfected groups. The difference in miR-182 level between infected group and uninfected group was statistically significant, and infected group had a higher miR-182 level in comparison with uninfected group $(\mathrm{P}<0.05)$. In both infected group and uninfected group, expression level of miR-182 in premature infants with brain injury was higher than that in premature infants without brain injury $(\mathrm{P}<0.05)$ (Fig. 1).

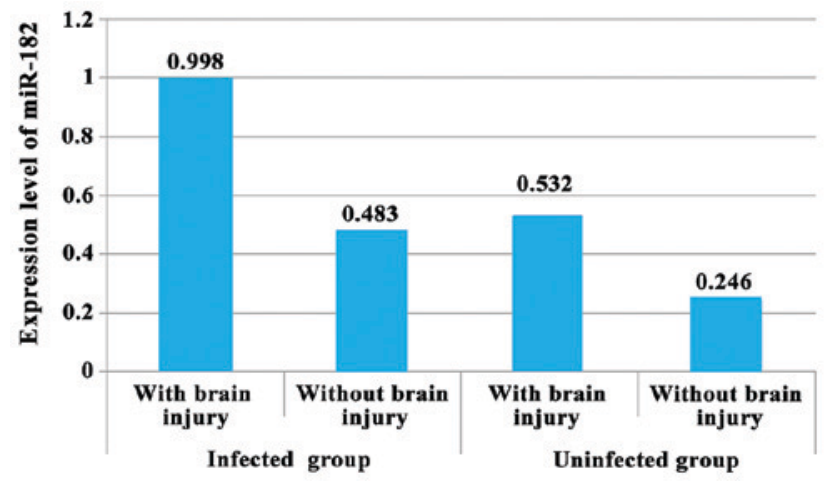

Figure 1. Expression level of miR-182 in infected and uninfected groups According to qPCR results, expression level of miR-182 in infected group is higher than that in uninfected group (infected vs. uninfected; $\mathrm{P}=0.023$ ); in infected group, pre-term infants with brain injury have higher expression levels of miR-182 in comparison with those without brain injury (with brain injury vs. without brain injury; $\mathrm{P}=0.033$ ); in uninfected group, expression level of miR-182 in premature infants with brain injury is higher than that in premature infants without brain injury (with brain injury vs. without brain injury; $\mathrm{P}=0.042$ )

Table IV. Univariate COX regression analysis of brain injury in premature infants.

\begin{tabular}{lccc}
\hline & \multicolumn{3}{c}{ Single factor } \\
\cline { 2 - 4 } Indicator & HR & $95 \%$ CI & P-value \\
\hline miR-182 (high vs. low) & 1.674 & $1.134-2.869$ & 0.01 \\
Gestational age (weeks) & 1.051 & $0.989-1.038$ & 0.061 \\
Sex (male vs. female) & 0.893 & $0.274-2.452$ & 0.779 \\
Body weight & 0.832 & $0.376-1.864$ & 0.672 \\
Intrauterine infection & 2.226 & $0.937-147.46$ & 0.003 \\
Placental infection & 3.053 & $1.233-7.345$ & 0.026 \\
\hline
\end{tabular}

HR, hazard ratio; CI, confidence interval.

Table V. Multivariate COX regression analysis of brain injury in premature infants.

\begin{tabular}{lccc}
\hline & \multicolumn{3}{c}{ Multi-factor } \\
\cline { 2 - 4 } Indicator & HR & $95 \%$ CI & P-value \\
\hline miR-182 (high vs. low) & 1.969 & $0.951-4.077$ & 0.012 \\
Intrauterine infection & 1.639 & $0.832-3.695$ & 0.002 \\
Placental infection & 1.268 & $0.918-2.471$ & 0.001 \\
\hline
\end{tabular}

HR, hazard ratio; CI, confidence interval.

Multivariate COX regression analysis of brain injury in premature infants. The median of miR-182 expression level in 89 premature infants with brain injury was 0.723 , these infants were divided into high expression group with miR-182 $\geq 0.723$ and low expression group with miR-182<0.723; expression 
level of miR-182 and placental infection were independent risk factors of brain injury in premature infants; intrauterine infection was closely related to brain injury in premature infants; and risk value of brain injury in premature infants caused by intrauterine infection was hazard ratio $(\mathrm{HR})=2.226$, $\mathrm{P}=0.003$ (Tables IV and V).

\section{Discussion}

Despite the average neonatal mortality rate has declined year by year since 1990 , there are still $\sim 3,000,000$ neonates who die every year (12). Intrauterine infection is one of the important risk factors for neonatal sepsis and is a common cause of neonatal infant mortality and morbidity, especially for premature infants (13). Intrauterine infection is a leading cause of premature birth and brain injury, bacterial invasions in chorion and amnion or placenta can lead to fetal inflammatory response, which has significant adverse effects on growth of fetal brains (14).

This study explored relationships of miR-182 expression level with intrauterine infection and brain injury in premature infants via examinations of miR-182 expression level in amniotic fluid. In this study, premature infants who had a time of pregnancy termination of $<35$ weeks and whose mother did not have preeclampsia and diabetes mellitus were included. This study was approved by the medical Ethics Committee of the hospital. Patients or their families signed the informed consent.

In this study, the analysis of expression level of miR-182 via $\mathrm{qPCR}$ showed that pregnant women with intrauterine infection had a clearly higher miR-182 expression level in amniotic fluid in comparison with those without intrauterine infection $(\mathrm{P}<0.05)$, suggesting that miR-182 expression level is associated with intrauterine infection. At present, no studies on association of miR-182 expression level with intrauterine infection and brain injury in premature infants are found. This study is for reference only. The study of Hanke et al (15) showed that the level of miR-182 expression in bladder epithelial carcinoma complicated with urinary tract infection was also increased. Therefore, miR-182 is closely related to infection. Kelada et al (16) found that in schistosome and leishmania-related inflammatory stages, IL-4 can upregulate miR-182 expression level via the transcription factor macrophage activating factor (cMaf), phosphorylation status of cMaf and other pathways including IL-2 and other transcriptional regulators may also have impact on miR-182. Stittrich et al (17) indicated that miR-182 is closely related to the activity of helper T lymphocytes. IL-2 induces the increase of miR-182 level and promotes the expansion of helper $\mathrm{T}$ lymphocytes. Later, further studies are needed to confirm whether intrauterine infection in pregnant women can also regulate miR-182 expression level through this mechanism. Present studies have confirmed (18-22) that intrauterine infection can cause brain damage in premature infants. Therefore, expression level of miR-182 is closely related to brain injury in premature infants. The results of this study also revealed that miR-182 expression level in infants with brain injury was higher than that in infants without brain injury $(\mathrm{P}<0.05)$. In this study, differences in miR-182 expression levels in preterm infants and extremely preterm infants as well as various degrees of brain damage were not investigated, which are worth exploring in the future.

The results of this study also indicated that among infants delivered by pregnant women without intrauterine infection, infants with brain injury had a higher miR-182 expression level in comparison with those without brain injury $(\mathrm{P}<0.05)$, suggesting that miR-182 may have an independent impact on brain injury in premature infants; COX regression analysis also revealed that miR-182 expression level is an independent risk factor for brain injury in premature infants. miR-182 is a member of miR-183 cluster (miR-183, miR-182 and miR-96). Yi et al (23) found that miR-182 aggravates cerebral ischemic injury by targeting an inhibitor of apoptosis-stimulating protein of p53 (iASPP) the ASPP family. Ding et al (24) established models of rats with brain injury and also found abnormalities in miR-182 expression. These have further confirmed that miR-182 is involved in the occurrence of brain injury.

At present, studies on miR-182 have also found that it affects the occurrence and development of tumors. Spitschak et al (25) found that miR-182 can promote cancer invasion by rearranged during transfection (RET) oncogene-activated nuclear factor $\kappa$-light-chain-enhancer of activated B cells $(\mathrm{NF}-\kappa \mathrm{B})$ and HES1/Notch1 regulatory pathway. Xu et al (26) also found that miR-182, the target gene of the long non-coding RNA death associated protein kinase1 (DAPK1), participates in the invasion and metastasis of pancreatic cancer by modulating Ras homolog gene family-associated coiled-coil containing protein kinase 1 (ROCK-1)/ Rho, member A (RhoA) signaling pathway. Yu et al (27) found that miR-182 promotes the development of breast cancer via targeted regulation of forkhead box protein F2 (FOXF2). These are part of the latest studies on associations of miR-182 with the occurrence and development of tumors so far, suggesting that miR-182 is a multifunctional molecule. Whether it also plays roles in other diseases is worth exploring further.

In conclusion, intrauterine infection can cause an increase in miR-182 level; growth in miR-182 level and brain injury in premature infants are closely related.

\section{Acknowledgements}

Not applicable.

\section{Funding}

No funding was received.

\section{Availability of data and materials}

The datasets used and/or analyzed during the present study are available from the corresponding author on reasonable request.

\section{Authors' contributions}

FG, XJ and KF conceived and designed the study. FG and QL were responsible for the collection and analysis of the patient data. FG and XJ interpreted the data and drafted the manuscript. KF revised the manuscript critically for important intellectual content. All authors read and approved the final study. 


\section{Ethics approval and consent to participate}

The study was approved by the Ethics Committee of Jinan Maternity and Child Care Hospital (Shandong, China). Signed informed consents were obtained from the parents of the infants.

\section{Patient consent for publication}

Not applicable.

\section{Competing interests}

The authors declare that they have no competing interests.

\section{References}

1. Kemp MW: Preterm birth, intrauterine infection, and fetal inflammation. Front Immunol 5: 574, 2014.

2. Sarno M, Sacramento GA, Khouri R, do Rosário MS, Costa F, Archanjo G, Santos LA, Nery N Jr, Vasilakis N, Ko AI, et al: Zika virus infection and stillbirths: A case of hydrops fetalis, hydranencephaly and fetal demise. PLoS Negl Trop Dis 10 e0004517, 2016

3. Higgins RD, Saade G, Polin RA, Grobman WA, Buhimschi IA, Watterberg K, Silver RM and Raju TN; Chorioamnionitis Workshop Participants: Evaluation and management of women and newborns with a maternal diagnosis of chorioamnionitis: Summary of a workshop. Obstet Gynecol 127: 426-436, 2016.

4. Salmaso N, Jablonska B, Scafidi J, Vaccarino FM and Gallo V: Neurobiology of premature brain injury. Nat Neurosci 17: 341-346, 2014.

5. Ball G, Boardman JP, Rueckert D, Aljabar P, Arichi T, Merchant N, Gousias IS, Edwards AD and Counsell SJ: The effect of preterm birth on thalamic and cortical development. Cereb Cortex 22: 1016-1024, 2012.

6. Hagberg H, Mallard C, Ferriero DM, Vannucci SJ, Levison SW, Vexler ZS and Gressens P: The role of inflammation in perinatal brain injury. Nat Rev Neurol 11: 192-208, 2015.

7. Weeraratne SD, Amani V, Teider N, Pierre-Francois J, Winter D, Kye MJ, Sengupta S, Archer T, Remke M, Bai AH, et al: Pleiotropic effects of miR-183 96 182 converge to regulate cell survival, proliferation and migration in medulloblastoma. Acta Neuropathol 123: 539-552, 2012.

8. Song L, Liu L, Wu Z, Li Y, Ying Z, Lin C, Wu J, Hu B, Cheng SY, Li M, et al: TGF- $\beta$ induces miR-182 to sustain NF- $\kappa$ B activation in glioma subsets. J Clin Invest 122: 3563-3578, 2012.

9. Kim CJ, Romero R, Chaemsaithong P, Chaiyasit N, Yoon BH and Kim YM: Acute chorioamnionitis and funisitis: Definition, pathologic features, and clinical significance. Am J Obstet Gynecol 213 (Suppl): S29-S52, 2015.

10. Roth TL, Nayak D, Atanasijevic T, Koretsky AP, Latour LL and McGavern DB: Transcranial amelioration of inflammation and cell death after brain injury. Nature 505: 223-228, 2014.

11. Livak KJ and Schmittgen TD: Analysis of relative gene expression data using real-time quantitative PCR and the 2(-Delta Delta C(T)) method. Methods 25: 402-408, 2001.

12. Lawn JE, Blencowe H, Oza S, You D, Lee AC, Waiswa P, Lalli M, Bhutta Z, Barros AJ, Christian P, et al; Lancet Every Newborn Study Group: Every Newborn: Progress, priorities, and potential beyond survival. Lancet 384: 189-205, 2014.
13. Greksova K, Parrak V, Chovancova D, Stencl P, Oravec J, Marsik L, Sysak R, Fuchs D, Peskova Z and Borovsky M: Procalcitonin, neopterin and C-reactive protein in diagnostics of intrauterine infection and preterm delivery. Bratisl Lek Listy 110 : 623-626, 2009.

14. Paton MCB, McDonald CA, Allison BJ, Fahey MC, Jenkin G and Miller SL: Perinatal brain injury as a consequence of preterm birth and intrauterine inflammation: Designing targeted stem cell therapies. Front Neurosci 11: 200, 2017.

15. Hanke M, Hoefig K, Merz H, Feller AC, Kausch I, Jocham D, Warnecke JM and Sczakiel G: A robust methodology to study urine microRNA as tumor marker: microRNA-126 and microRNA-182 are related to urinary bladder cancer. Urol Oncol 28: 655-661, 2010.

16. Kelada S, Sethupathy P, Okoye IS, Kistasis E, Czieso S, White SD, Chou D, Martens C, Ricklefs SM, Virtaneva K, et al: miR-182 and miR-10a are key regulators of Treg specialisation and stability during Schistosome and Leishmania-associated inflammation. PLoS Pathog 9: e1003451, 2013.

17. Stittrich AB, Haftmann C, Sgouroudis E, Kühl AA, Hegazy AN, Panse I, Riedel R, Flossdorf M, Dong J, Fuhrmann F, et al: The microRNA miR-182 is induced by IL-2 and promotes clonal expansion of activated helper T lymphocytes. Nat Immunol 11: 1057-1062, 2010

18. Masaoka N, Nakajima Y, Morooka M, Tashiro H, Wada M, Maruta K, Iwane E and Yamashiro M: The impact of intrauterine infection on fetal brain damage assessed by $\mathrm{S} 100 \mathrm{~B}$ protein concentrations in umbilical cord arteries. J Matern Fetal Neonatal Med 29: 2464-2469, 2016

19. Sameshima H and Ikenoue T: Developmental effects on neonatal mortality and subsequent cerebral palsy in infants exposed to intrauterine infection. Early Hum Dev 83: 517-519, 2007.

20. Zhao J, Chen Y, Xu Y and Pi G: Effect of intrauterine infection on brain development and injury. Int J Dev Neurosci 31: 543-549, 2013.

21. Burd I, Balakrishnan B and Kannan S: Models of fetal brain injury, intrauterine inflammation, and preterm birth. Am J Reprod Immunol 67: 287-294, 2012.

22. Elovitz MA, Brown AG, Breen K, Anton L, Maubert M and Burd I: Intrauterine inflammation, insufficient to induce parturition, still evokes fetal and neonatal brain injury. Int $\mathrm{J}$ Dev Neurosci 29: 663-671, 2011.

23. Yi H, Huang Y, Yang F, Liu W, He S and Hu X: MicroRNA-182 aggravates cerebral ischemia injury by targeting inhibitory member of the ASPP family (iASPP). Arch Biochem Biophys 620: 52-58, 2017.

24. Ding X, Sun B, Huang J, Xu L, Pan J, Fang C, Tao Y, Hu S, Li R, Han $\mathrm{X}$, et al: The role of miR-182 in regulating pineal CLOCK expression after hypoxia-ischemia brain injury in neonatal rats. Neurosci Lett 591: 75-80, 2015.

25. Spitschak A, Meier C, Kowtharapu B, Engelmann D and Pützer BM: miR-182 promotes cancer invasion by linking RET oncogene activated $\mathrm{NF}-\kappa \mathrm{B}$ to loss of the HES1/Notch1 regulatory circuit. Mol Cancer 16: 24, 2017.

26. Xu X, Wang X and Geng C: Long-chain non-coding RNA DAPK1 targeting miR-182 regulates pancreatic cancer invasion and metastasis through ROCK-1/rhoa signaling pathway. Int J Clin Exp Pathol 10: 9273-9283, 2017.

27. Yu J, Shen W, Gao B, Zhao H, Xu J and Gong B: MicroRNA-182 targets FOXF2 to promote the development of triple-negative breast cancer. Neoplasma 64: 209-215, 2017.

This work is licensed under a Creative Commons Attribution-NonCommercial-NoDerivatives 4.0 International (CC BY-NC-ND 4.0) License. 